\title{
Laryngeal stent for acute and chronic respiratory distress in seven dogs with laryngeal paralysis
}

\author{
María Cecilia Ricart ${ }^{1,2 *}$, Sergio Martín Rodríguez $z^{1,3}$ and Roberto Miguel Duré ${ }^{4}$ \\ ${ }^{1}$ Veterinary Endoscopy and Anesthesiology in Small Animals, Private Practice, CABA, Argentina \\ ${ }^{2}$ Universidad de Buenos Aires, Facultad de Ciencias Veterinarias, Cátedra de Clínica Médica de Pequeños \\ Animales, Av. Chorroarín 280, C1417CWO CABA, Argentina \\ ${ }^{3}$ Universidad de Buenos Aires, Facultad de Ciencias Veterinarias, Cátedra de Anestesiología y Algeología, Av. \\ Chorroarín 280, C1417CWO, CABA, Argentina \\ ${ }^{4}$ Unidad de Endoscopia Peroral Hospital de Infecciosas “F. Muñiz”, Uspallata 2272, C1282AEN CABA, Argentina
}

\begin{abstract}
Background: Laryngeal paralysis, failure of arytenoid cartilage, and vocal fold abduction are commonly seen in older medium to large breed dogs. Observation of laryngeal function in dogs and cats is performed by transoral visualization. There are a variety of surgical techniques; aspiration pneumonia is the most common complication associated with surgical correction of laryngeal paralysis. The aim of this case series is to report on the placement of a laryngeal silicone stent in seven dogs with laryngeal paralysis and its use as an alternative treatment of respiratory distress caused by laryngeal paralysis and/or its use for laryngeal stenosis as complication of laryngeal paralysis surgery.

Case description: Seven dogs presented with either episode of gagging, mild-to-severe inspiratory distress, or cyanosis because of a laryngeal paralysis or laryngeal stenosis. In each case, the laryngeal paralysis was diagnosed by direct laryngoscopy. They were treated with a silicone laryngeal stent (Stening ${ }^{\circledR}$ ) that substantially improved the clinical signs. Each dog had a different outcome because of other pathologies; however, the laryngeal pathology was successfully treated with the stent.

Conclusion: The placement of the laryngeal stent is an easy technique to learn and practice, it could avoid the lifethreatening complications of the laryngeal paralysis at the acute phase, and it could be a noninvasive and long-term alternative therapy for laryngeal paralysis in dogs. The results in these clinical cases are encouraging for considering the laryngeal stent as a therapeutic alternative.
\end{abstract}

Key words: Canine, Polyneuropathy, Prosthesis, Surgery.

\section{Introduction}

Laryngeal paralysis, failure of arytenoid cartilage, and vocal fold abduction are commonly seen in older medium to large breed dogs (Burbridge, 1995; MacPhail and Monnet, 2009; Millard and Tobias, 2009; Monnet, 2009). Uni- and bilateral paresis or paralysis of the laryngeal muscles has been reported in dogs, cats, and horses. Unilateral paralysis results in moderate inspiratory dyspnea and inspiratory noise. Bilateral paralysis leads to episodes of gagging, cyanosis, severe inspiratory dyspnea, and collapse. The diagnosis of laryngeal paralysis is relatively straightforward and it is based on the observation of the larynx during all phases of respiration. Normally, the vocal cords and arytenoid cartilage abduct during inspiration (MacPhail and Monnet, 2009; Millard and Tobias, 2009; Lorenz et al., 2011).

An observation of laryngeal function in dogs and cats is performed using transoral visualization (Radlinsky et al., 2004). The observation of the vocal cords and arytenoids displaying inadequate abduction during inspiration or remaining in a paramedian position is consistent with a diagnosis of laryngeal paresis or paralysis, respectively. Paradoxical movement of the vocal cords can occur in animals with pronounced inspiratory effort giving the false impression of motion (Kitshoff et al., 2013). Consequently, an assistant should aid the evaluation by telling the examiner when the animal inhales and exhales. The depth of anesthesia and choice of anesthetics are critical for proper evaluation, and an alternative anesthetic includes propofol (Jackson et al., 2004). If doubts are encountered during evaluation, doxapram, a centrally acting respiratory stimulant, may aid in the diagnosis of laryngeal paralysis in dogs by increasing the respiratory effect and possibly increasing arytenoid cartilage movements (Miller et al., 2002; Tobias et al., 2004; Lorenz et al., 2011).

The dog should be provided with supplemental oxygen during the initial assessment, and in most cases, sedation will be needed (Millard and Tobias, 2009). At the emergency consultation, low doses of acepromazine (0.03-0.05 $\mathrm{mg} / \mathrm{kg}$ intravenously (IV)) alone or in combination with butorphanol $(0.1 \mathrm{mg} / \mathrm{kg} \mathrm{IV})$ are often

*Corresponding Author: Maria Cecilia Ricart. Universidad de Buenos Aires, Facultad de Ciencias Veterinarias, Cátedra de Clínica 
effective to reduce the respiratory anxiety (Sigrist, 2011; Sharp and Rozanski, 2013). Sedation is beneficial in the dynamic obstruction by reducing the anxiety associated with inspiration because, with increased inspiratory efforts, there is a resulting paradoxical decline in airway diameter. Dogs that do not rapidly improve with sedation should be anesthetized and intubated. If palliative surgery is not readily available, dogs may require a tracheostomy or may be kept briefly sedated or intubated until eupnea ensues. Dogs are commonly maintained on a constant rate infusion (CRI) of propofol $(0.2-0.5 \mathrm{mg} / \mathrm{kg} /$ minute) titrated to effect for 30-60 minutes. If, after this period, a dog cannot be extubated, due to the higher risk of aspiration pneumonia, it is better to perform a tracheostomy than keep the dog intubated. The exception to this rule is when surgery may be performed within a few hours (Sharp and Rozanski, 2013). Severely affected dogs should be treated by surgical correction aimed at enlarging the rim glottis without altering the ability to close the glottis during swallowing.

There are a variety of surgical techniques. In general, unilateral arytenoid cartilage lateralization (Snelling and Edwards, 2003) is preferred over bilateral arytenoid lateralization or partial laryngotomy (MacPhail and Monnet, 2001). Postoperatively, most of the dogs experience improvement or resolution of clinical signs. Aspiration pneumonia is the most common complication associated with surgical correction of laryngeal paralysis (Millard and Tobias, 2009; Kitshoff et al., 2013).

The aim of this article is to report on the placement of a laryngeal silicone stent in seven dogs and its use as an alternative treatment of respiratory distress caused by laryngeal paralysis and/or its use for laryngeal stenosis as complication of laryngeal paralysis surgery. It is a noninvasive technique. In all cases, the owners signed an informed consent for the animal subjects participating in the research and its possible publication. A tracheal stent (tracheal 14-40, Stening ${ }^{\circledR}$, Buenos Aires, Argentina) molded in flexible silicone in a single, nonframe piece was selected for all cases
(Fig. 1A). The dog is placed in sternal recumbency with an elevated head. Oxygen facemask as preoxygenation with 3-minute breathing oxygen at $100 \mathrm{ml} / \mathrm{kg} / \mathrm{min}$ is necessary (Soro Domingo et al., 2004; McNally et al., 2009) for every procedure. With a $20-\mathrm{cm}$ long Allis forceps, the stent is compressed as shown in the picture (Fig. 1B) and lubricated with jelly lidocaine $2 \%$. The procedure is performed under sedation with titrated propofol 4-8 $\mathrm{mg} / \mathrm{kg}$ IV to effect. When possible, the mouth should be opened and the tongue withdrawn while the Allis, with the stent in its end, is placed into the lumen of the larynx and liberated. The prominences of the stent should be placed cranial to the vocal folds for fixation, the arytenoid cartilages should be opened with its walls, and it should be checked that the movement of the epiglottis is possible. If needed, the Allis could be used to accommodate the stent once it is placed in the glottis. The stent usually does not need any other fixation than the prominences cranial to the vocal cords if the arytenoid cartilages fail to abduce. The stent is shown in X-rays. The same technique is used in laryngeal stenosis, complication due to cordectomy; in this case, the stent is fixed by the stenosis itself.

Once the stent is placed, titrated propofol IV is suspended and an oxygen face mask is again used until the dog recovers. It is necessary to check if the stent is correctly placed during this time. It might provoke a discrete cough immediately after waking, and no abnormal breathing sounds should be heard (no stridor nor noisy breathing) (Fig. 2). If there is any doubt about its placement, transoral laryngoscopy should be performed immediately.

After the procedure, depending on the clinical condition and the owner's choice, the dog could go home or remain in hospital. Two to three hours after the procedure, water can be offered. If the dog does not cough while drinking, the stent is perfectly placed. If the dog coughs while drinking, wet food should be offered until the stent is accommodated properly by the swallowing reflex itself. The stent is visible by X-ray as shown in Fig. 3.
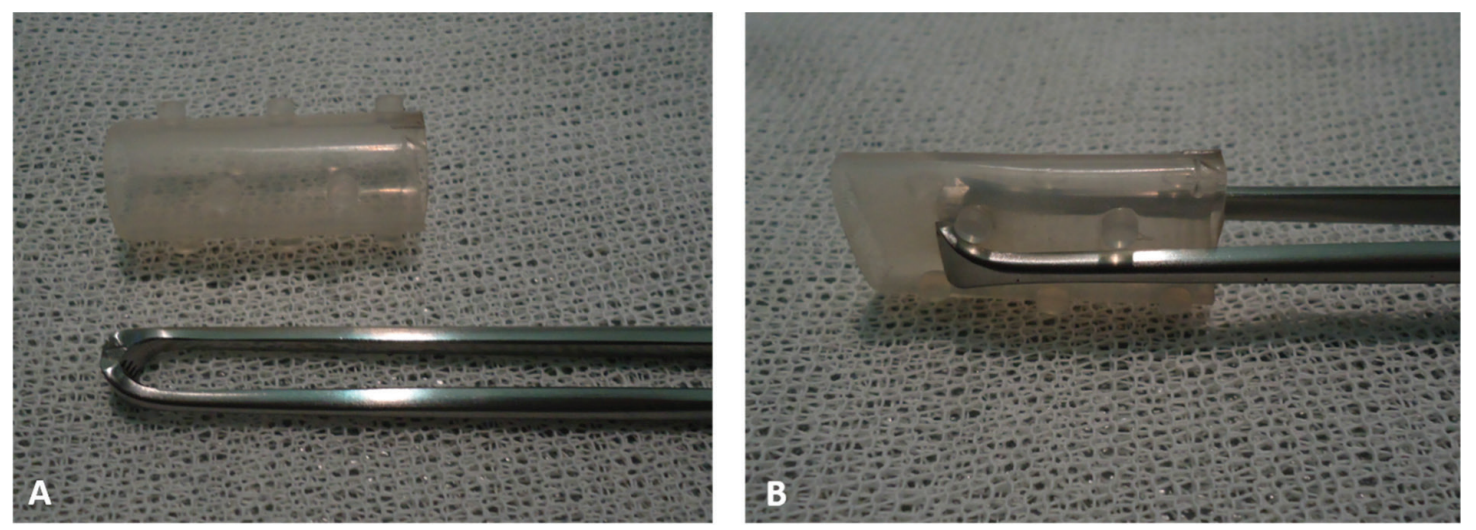

Fig. 1. (A) Silicone stent (in the upper side) and Allis forceps. (B) Allis forceps compressing the stent, as it is collocated. 


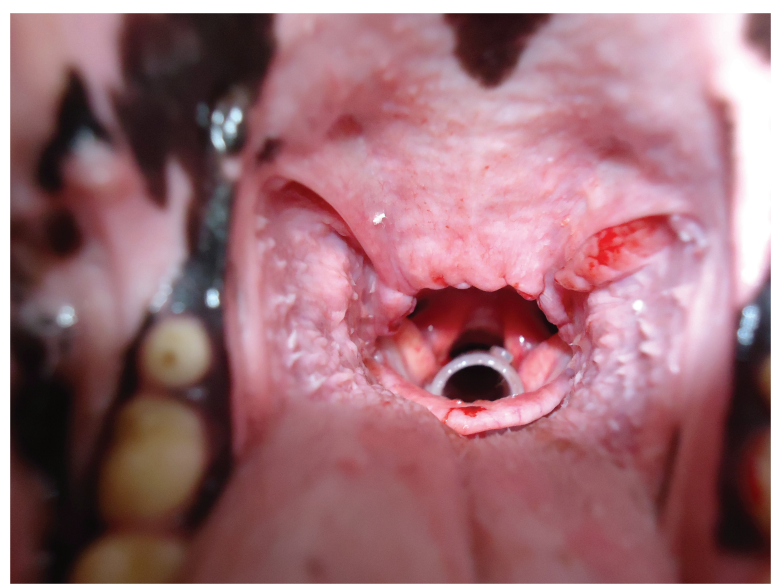

Fig. 2. View of the laryngeal stent during a transoral laryngoscopy, after palatoplasty

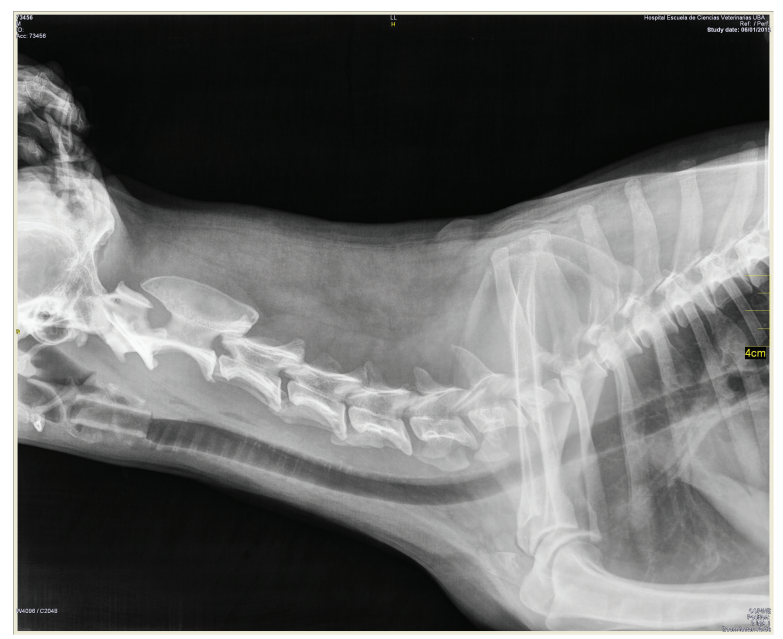

Fig. 3. Neck latero-lateral X-ray: correct position of the laryngeal stent.

\section{Case Details}

Seven dogs with laryngeal paralysis and other comorbidities were diagnosed and treated with a silicone laryngeal stent (in all cases, a tracheal 14-40 was used, Stening ${ }^{\circledR}$ ). All the dogs, except for the Brittany Spaniel, underwent a blood scan, chest radiographs, and cardiological tests as a preanesthetic checkup before the stent placement. The Brittany Spaniel was assisted at the emergency room with respiratory distress and the treatment was decided under the diagnostic anesthesia. In all cases, a transoral laryngoscopy confirmed the diagnosis of laryngeal paralysis, and in some cases, other pathologies were also diagnosed.

In all cases, different surgical treatments were discussed with the owners. However, these owners did not want an invasive procedure because of the advance age of the dogs and a laryngeal silicone stent was placed as an alternative for the laryngeal pathology therapy. An informed consent was signed in all cases. Clinical cases consisted of acute or chronic respiratory distress. Dog's number 1,2, and 3 had a respiratory crisis that needed emergency assistance; the three dogs presented stridor and bad-to-mild general condition. In these cases, the owners informed previous exercise intolerance and corticosteroid treatment with no resolution. The owner of dog number 3 referred a mass ventral to the neck that had appeared 5 months before. The owners of dog's number 4 and 5 informed mild respiratory distress and exercise intolerance for some time. The owners of dog's number 6 and 7 recognized new respiratory distress after normal breathing after a laryngeal surgery, ventriculocordectomy, and palatoplasty performed for laryngeal paralysis and elongated soft palate before. Clinical cases are summarized in Table 1. At consultation, transoral laryngoscopy confirmed the diagnosis of laryngeal paralysis in all cases. Elongated soft palate was also diagnosed in dog's number 1,3 , and 5 , whereas, only in dog 1 , everted saccules were observed. In dogs 6 and 7, laryngeal stenosis was diagnosed. Clinically, dog's number 1 and 2 were suspected to have a polyneuropathy, but it was not confirmed. In dog number 3 , a carcinoma was confirmed by mass cytology and chest X-ray confirmed pulmonary nodules. In dog's number $4,5,6$, and 7, hypothyroidism was confirmed by hormones.

In dogs that showed an elongated soft palate, first palatoplasty was performed under general anesthesia and second placement of the silicone stent was performed as described above (Fig. 5), with the exception of the Brittany Spaniel where stent placement was only therapeutic due to costs of the palatoplasty surgery (Fig. 4). Two dogs (dog's number 6 and 7) had prior to the laryngeal stent placement, a ventriculocordectomy through ventral laryngotomy, castellated laryngofissure, and palatoplasty because of laryngeal paralysis and elongated soft palate. The days after, the surgery normal respiratory sound was perceived, but the female Labrador Retriever coughed during water swallowing. Seven to ten days after the surgery, stridor relapsed in both the dogs. Laryngeal stenosis was confirmed in the glottis due to fibrosis reaction to the cordectomy. Thus, the laryngeal stent was placed for the treatment of the stenosis pathology and laryngeal paralysis. All dogs presented normal breathing sounds after the laryngeal stent placement. Case 1 was diagnosed with general megaesophagus and bronchopneumonia, regurgitation was constant, and euthanasia was performed for humanitarian reasons. The owners of dog's number 1 and 2 decided the euthanasia several days after the laryngeal treatment for economic reasons of the diagnostic etiology and progressive weakness. In both the dogs, the stent was retrieved from the larynx, and mild inflammatory reaction was observed. Diagnosis, treatment, and survival time for each clinical case are summarized in Table 2. 
Table 1. Signaling, consultation motive, evolution of the clinical signs, and clinical signs during consultation in seven dogs.

\begin{tabular}{|c|c|c|c|}
\hline Dog signaling & Consultation motive & Evolution of clinical signs & Clinical signs \\
\hline $\begin{array}{l}\text { 1) 14-year-old, intact female, } \\
\text { Brittani Spaniel }\end{array}$ & $\begin{array}{l}\text { Emergency: severe inspiratory } \\
\text { distress and weakness }\end{array}$ & 1 month & $\begin{array}{l}\text { Stridor, cyanosis, general } \\
\text { weakness, cachexia, bad } \\
\text { general condition }\end{array}$ \\
\hline $\begin{array}{l}\text { 2) 11-year-old, intact male, } \\
\text { Dalmatian }\end{array}$ & $\begin{array}{l}\text { Emergency: inspiratory and } \\
\text { expiratory distress with increased } \\
\text { breathing sounds }\end{array}$ & Uncertain & $\begin{array}{l}\text { Stridor, sarcopenia, bad } \\
\text { general condition }\end{array}$ \\
\hline $\begin{array}{l}\text { 3) } 13 \text {-year-old, neutered } \\
\text { female, Golden Retriever }\end{array}$ & $\begin{array}{l}\text { Emergency: severe inspiratory } \\
\text { distress and stridor }\end{array}$ & 2 weeks & $\begin{array}{l}\text { Stridor, mild general } \\
\text { condition }\end{array}$ \\
\hline $\begin{array}{l}\text { 4) 2-year-old, intact male, } \\
\text { Siberian Husky }\end{array}$ & $\begin{array}{l}\text { Mild inspiratory distress during } \\
\text { sleeping hours and exercise } \\
\text { intolerance }\end{array}$ & 3 months & $\begin{array}{l}\text { Noisy breathing while } \\
\text { panting, phonation } \\
\text { changes, stridor, good } \\
\text { general condition }\end{array}$ \\
\hline $\begin{array}{l}\text { 5) } 12 \text {-year-old, neutered } \\
\text { female, Labrador } \\
\text { Retriever }\end{array}$ & $\begin{array}{l}\text { Episodical stridor and occasional } \\
\text { exercise intolerance }\end{array}$ & 1 month & $\begin{array}{l}\text { Stridor, cervical pain, mild } \\
\text { general condition }\end{array}$ \\
\hline $\begin{array}{l}\text { 6) } 13 \text {-year-old, intact male, } \\
\text { Alaskan Malamute }\end{array}$ & $\begin{array}{l}\text { Inspiratory distress } \\
\text { (ventriculocordectomy through } \\
\text { ventral laryngotomy, castellated } \\
\text { laryngofissure, and palatoplasty } \\
\text { were performed } 30 \text { days before) }\end{array}$ & 1 week & $\begin{array}{l}\text { Stridor, good general } \\
\text { condition }\end{array}$ \\
\hline $\begin{array}{l}\text { 7) 11-year-old, intact female, } \\
\text { Labrador Retriever }\end{array}$ & $\begin{array}{l}\text { Stridor and occasionally inspiratory } \\
\text { distress (ventriculocordectomy } \\
\text { laryngofissure, and ventral } \\
\text { laryngotomy, castellated } \\
\text { laryngofissure, and palatoplasty } \\
\text { were performed } 40 \text { days before) }\end{array}$ & 10 days & $\begin{array}{l}\text { Stridor, good general } \\
\text { condition }\end{array}$ \\
\hline
\end{tabular}

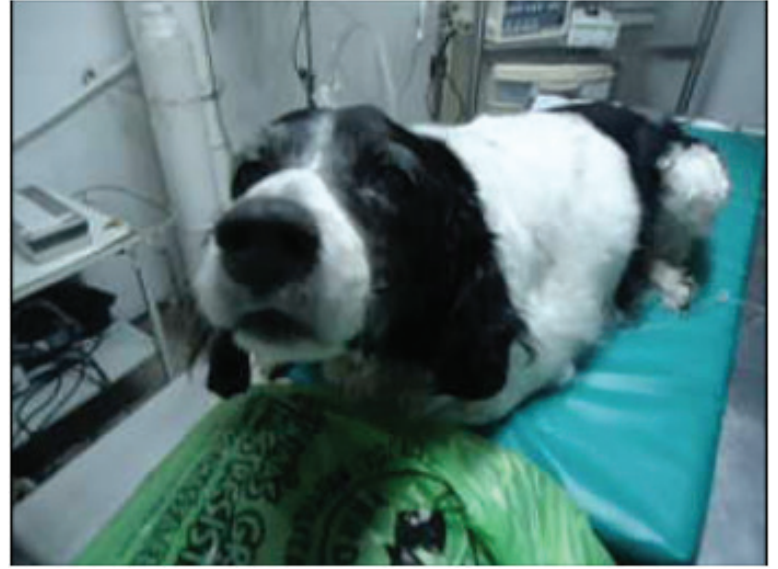

Fig. 4. Notice the anxious face of case description number 2, Brittany Spaniel, before the procedure.

\section{Discussion}

Canine acquired idiopathic laryngeal paralysis is a common condition affecting older, usually large-breed dogs, in which almost all the intrinsic muscles of the larynx become paralyzed (Stanley et al., 2010). Laryngeal paralysis causes an increased resistance to airflow and therefore creates turbulence and abnormal negative pressures in the glottis. Surgical

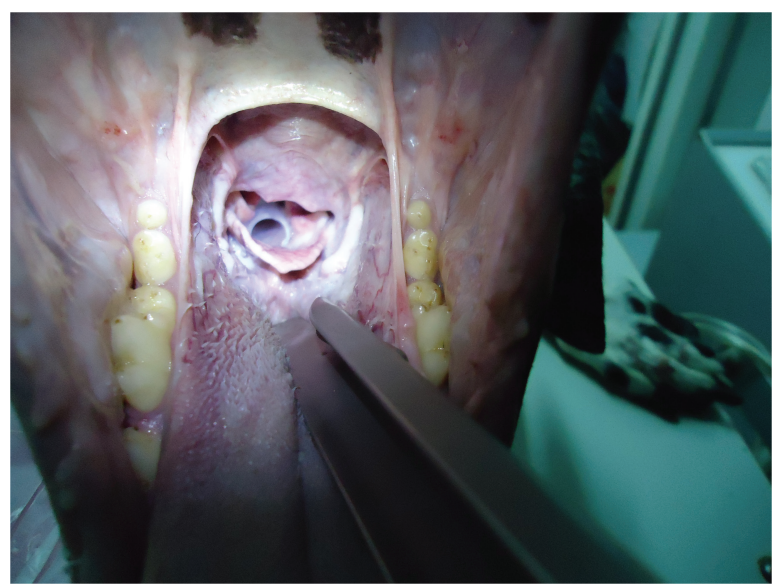

Fig. 5. Correct position of the stent.

techniques were reported as a successful treatment for long-term management of laryngeal paralysis, but each surgical technique has its complications (Nelisen and White, 2012). In addition, many owners of these dogs want a noninvasive procedure to improve the respiratory distress and they would like to improve the quality of life without performing surgery or, in some cases, the surgery option is not available in the emergency situation. Many procedures have been 
Table 2. Description of diagnosis, treatment, and survival time in the same seven dogs described in Table 1, the same order of appearance is used.

\begin{tabular}{|c|c|c|c|}
\hline Dog number & Diagnosis & Treatment & Survival \\
\hline 1) Brittani Spaniel & $\begin{array}{l}\text { Laryngeal paralysis, everted } \\
\text { laryngeal saccules, and } \\
\text { elongated soft palate }\end{array}$ & $\begin{array}{l}\text { Laryngeal stent, emergency } \\
\text { placing (for economical } \\
\text { reasons, palatoplasty and } \\
\text { everted saccules surgery were } \\
\text { not performed) }\end{array}$ & 7 days, euthanasia \\
\hline 2) Dalmatian & Laryngeal paralysis & Laryngeal stent & 10 days, euthanasia \\
\hline 3) Golden Retriever & $\begin{array}{l}\text { Carcinoma (presumably } \\
\text { thyroid), laryngeal paralysis, } \\
\text { pulmonary nodules }\end{array}$ & Laryngeal stent & $\begin{array}{l}85 \text { days, euthanasia } \\
\text { (no stridor, the pulmonary } \\
\text { nodules worsened) }\end{array}$ \\
\hline 4) Siberian Husky & $\begin{array}{l}\text { Elongated soft palate and } \\
\text { laryngeal paralysis }\end{array}$ & Palatoplasty and laryngeal stent & 22 months \\
\hline 5) Labrador Retriever & $\begin{array}{l}\text { Elongated soft palate, laryngeal } \\
\text { paralysis, and spondylosis } \\
\text { deformans }\end{array}$ & Palatoplasty and laryngeal stent & 30 months and still alive \\
\hline 6) Alaskan malamute & $\begin{array}{l}\text { Laryngeal stenosis due to } \\
\text { fibrosis and laryngeal paralysis }\end{array}$ & Laryngeal stent & 12 months \\
\hline 7) Labrador Retriever & $\begin{array}{l}\text { Laryngeal stenosis due to } \\
\text { fibrosis and laryngeal paralysis }\end{array}$ & Laryngeal stent & 15 months and still alive \\
\hline
\end{tabular}

performed in human medicine to treat respiratory tract obstruction (Isidoro, 2012). In these circumstances, the laryngeal stent used in human medicine is a promising option for the laryngeal paralysis treatment, especially in older dogs. All the dogs that received the laryngeal stent improved their clinical respiratory sounds.

The cause of laryngeal paralysis may be idiopathic, congenital, traumatic, neoplastic, or iatrogenic (Wykes, 1983; White, 1989). Recent evidence strongly suggests that dogs with idiopathic laryngeal paralysis may have an underlying chronic progressive polyneuropathy (Stanley et al., 2010). Other acquired forms of laryngeal paralysis have been associated with injury to the vagus nerve during neck surgery, lead and organophosphate toxicity, or retropharyngeal infection. Hypothyroidism may cause polyneuropathy with concurrent laryngeal paralysis. Dogs without an identifiable underlying neuromuscular disease are classified as idiopathic laryngeal paralysis. Given that the illness originates in a progressive polyneuropathy, the clinical signs of noisy breathing will have been present for some time before a crisis. Crises often occur during the first hot and humid days of the spring or summer and may be associated with exercise. As the clinical signs develop slowly, the owners do not notice changes until severe inspiratory dyspnea or cyanosis is encountered and an emergency consultation is needed (Kitshoff et al., 2013).

All the dogs included in this study presented the signalment and clinical signs with recognized predisposition to laryngeal paralysis. Typical age in average is 11 years (range 8-14), and breed predisposition includes Labrador Retriever, Greyhounds, Golden Retriever, German Shepherd dogs, Brittany Spaniel, and also mixed breeds. All the dogs had a variety and duration of clinical signs from gradual onset of stridor and exercise intolerance to voice change, gagging, and weakness as described for the pathology (Millard and Tobias, 2009; Kitshoff et al., 2013).

The laryngeal stent that was used in these cases requires a short placement procedure; once the veterinarian becomes experienced in the technique, the correct placement should take 1 minute. This technique could be used in acute or chronic respiratory distress because of laryngeal paralysis, and the recovery is immediate. The placement of the stent could be used until surgery can be performed or it could be used as a long-term therapy as presented in these clinical cases.

The prognosis of the long-term therapy with laryngeal stent depends on the evolution of the clinical signs and severity of the acute episode. Clinical cases with mild-to-moderate clinical signs, less comorbidities, and shorter clinical evolution (cases 4, 5, 6, and 7) had better prognosis and survival time than dogs with severe, sustained inspiratory distress for longer periods, who needed emergency assistance (cases 1, 2, and 3). The seven cases presented in this report had a satisfactory quality of life with the laryngeal stent. Cases 4 to 7 had a long-term survival time with normal respiratory sound with the stent.

Case 4 had a carcinoma in the neck, presumably the vagus nerve was affected because of tumor, and normal breathing sounds were perceived for 85 days after placement. The owners asked for the euthanasia because of constant panting, and pulmonary metastasis was suspected with chess X-rays from the first consultation. Two dogs presented a laryngeal stenosis 
after cordectomy, a possible complication of the surgery (cases 6 and 7); the stent was placed to open the respiratory tract.

The expected clinical sign after the laryngeal stent placement is cough, as it is a foreign body in the larynx. Mild-to-moderate cough was described by all owners; in all cases, they considered that the cough was bearable with no suffering for the animal and agreed on a better quality of life for their dogs. Expectoration is also expected; only one dog (number 5) expectorated secretions while the other dogs swallowed them. Another observation of some owners was halitosis (dog's number 5 and 7). Candida contamination of the silicone stent is described in human medicine, and no culture or cytology of the secretion surrounding the stent was made in any cases. One owner requested a hygiene procedure twice (dog number 5), 2 and 6 months after the placement, due to halitosis. A mild-to-moderate secretion was adhered to the stent. It was removed, cleaned with a hypochlorite solution and $\mathrm{NaCl} 0.9 \%$ solution, and replaced under sedation. Laryngeal mucosa had a moderate inflammatory reaction. Four months later, the cleaning procedure was performed again and no complications were encountered. The last clinical control, 18 months after the placement, showed no respiratory noises or distress being present; the cough twice a day and mild halitosis were mentioned by the owners. The dog died 22 months after the stent placement.

Migration is a possible complication of the laryngeal stent. Oral migration occurred within the first 4 hours of placement in one dog, case 3. Replacement of the same stent was programed for the next day, and no other complications were observed. If the stent is well placed, it should not migrate because it is firmly placed within the arytenoid cartilages that are paralyzed and supported with the vocal cords (or the laryngeal fibrotic stenosis in cases where a cordectomy was performed). If the stent migrates, the original stridor would be heard again, and if there is any doubt, the visualization with a neck latero-lateral X-ray will evidence the location. The dog can be sedated to replace the stent. If it migrates, it would be expected to move into the oral cavity; therefore, it can be retrieved with the Allis forceps and placed again or it could be swallowed and defecated due to its compressible material. A mild cough is anticipated, but the stridor should not be heard after a correct placement. If migration occurs again, laryngomalacia with laryngeal collapse should be reevaluated. No complications were encountered by cough or secretions in any dogs.

The placement of the laryngeal stent in acute and chronic laryngeal paralysis is promising. All respiratory signs were resolved with the laryngeal stent. However, in those clinical cases that the laryngeal paralysis was diagnosed in acute respiratory distress with a long history of stridor or exercise intolerance and/or had other severe comorbidities, the evolution of the stent therapy was shorter.

The ease of placement and the immediate- and long-term results in these seven cases encourage the use of the silicone laryngeal stent for laryngeal paralysis in older dogs as a therapeutic alternative. This new treatment for the laryngeal paralysis is a promising therapeutic alternative to the known laryngeal surgical techniques. All of the owners reported an improvement in the quality of their dog's life and were grateful for the opportunity of a noninvasive therapeutic option for the laryngeal paralysis.

\section{Acknowledgments}

The authors sincerely thank Stening SRL ${ }^{\circledR}$ Argentina for providing the stents.

\section{Conflict of interest}

The authors declare that there is no conflict of interest.

\section{Author's contribution}

María Cecilia Ricart $\mathrm{PhD}$ performed the diagnosis in all dogs and placed six of the seven stents. Sergio Martín Rodríguez veterinarian performed all the anesthetic procedures. Roberto Duré thought and taught the technique in the first dog. All the authors contributed for the manuscript.

\section{References}

Burbridge, H.M. 1995. A review of laryngeal paralysis in dogs. Br. Vet. J. 151, 71-82.

Isidoro, R. 2012. Repermeabilización de la vía aérea con prótesis traqueobronquiales 300 casos. Rev. Am. Med. Resp. 2, 38-43.

Jackson, A.M., Tobias, K., Long, C., Bartges, J. and Harvey, R. 2004. Effects of various anesthetic agents on laryngeal motion during laryngoscopy in normal dogs. Vet. Surg. 33(2), 102-106.

Kitshoff, A.M., Van Goethem, B., Stegen, L., Vandekerckhove, P. and de Rooster. H. 2013. Laryngeal paralysis in dogs: an update on recent knowledge. J. S. Afr. Vet. Assoc. 84(1), E1-9.

Lorenz, M.D., Coates, J. and Kent, M. 2011. Disorders of the face, tongue, esophagus, larynx, and ear. In Handbook of veterinary neurology, 5th ed. Eds., Lorenz, M.D., Coates, J. and Kent, M. St. Luis, MO: Elsevier Inc., pp: 282-306.

MacPhail, C.M. and Monnet, E. 2001. Outcome of and postoperative complications in dogs undergoing surgical treatment of laryngeal paralysis: 140 cases. J. Am. Vet. Med. Assoc. 218, 1949-1956.

MacPhail, C.M. and Monnet, E. 2009. Laryngeal diseases. In Current veterinary therapy. Ed., Kirk. Philadelphia, PA: Saunders, pp: 627-630.

McNally, E.M., Robertson, S.A. and Pablo, L.S. 2009. Comparison of time to desaturation between preoxygenated and nonpreoxygenated dogs following sedation with acepromazine maleate 
and morphine and induction of anesthesia with propofol. Am. J. Vet. Res. 70(11), 1333-1338.

Millard, R. and Tobias, K. 2009. Laryngeal paralysis in dogs. Compendium: continuing education for veterinarians, University of Tennessee, USA, 31(5): 212-219.

Miller, C.J., McKiernan, B.C., Pace, J. and Fettman, M.J. 2002. The effects of doxapram hydrochloride (dopram-V) on laryngeal function in healthy dogs. J. Vet. Intern. Med. 16(5), 524-528.

Monnet, E. 2009. Laryngeal paralysis: an evidencebased approach to surgical technique. In the proceedings of 2009 BSAVA congress, Birmingham, pp: 362-364.

Nelisen, P. and White, R. 2012. Arytenoid lateralization for management of combined laryngeal paralysis and laryngeal collapse in small dogs. Vet. Surg. 41, 261-265.

Radlinsky, M.G., Mason, D.E. and Hodgson, D. 2004. Transnasal laryngoscopy for the diagnosis of laryngeal paralysis in dogs. J. Am. Anim. Hosp. Assoc. 40, 211-215.

Sharp, C.R. and Rozanski, E.A. 2013. Physical examination of the respiratory system. Top. Companion Anim. Med. 28, 79-85.

Sigrist, N. 2011. Stabilisation of the emergency patient part I: airway and breathing. Eur. J. Companion Anim. Pract. 21, 13-21.
Snelling, S.R. and Edwards, G.A. 2003. A retrospective study of unilateral arytenoid lateralization in the treatment of laryngeal paralysis in 100 dogs. Aust. Vet. J. 81, 464-468.

Soro Domingo, M., Belda Nácher, F.J., Aguilar Aguilar, G., Ferrandis Comes, R., García-Raimundo, M. and Martínez Pons, V. 2004. Preoxygenation for anesthesia. Rev. Esp. Anestesiol. Reanim. 51(6), 322-327.

Stanley, B.J., Hauptman, J.G., Fritz, M.C., Rosenstein, D.S. and Kinns, J. 2010. Oesophageal dysfunction in dogs with idiopathic laryngeal paralysis: a controlled cohort study. Vet. Surg. 39, 139-149.

Tobias, K.M., Jackson, A.M. and Harvey, R.C. 2004. Effects of doxapram $\mathrm{HCl}$ on laryngeal function of normal dogs and dogs with naturally occurring laryngeal paralysis. Vet. Anaesth. Analg. 31(4), 258-263.

White, R.A.S. 1989. Unilateral arytenoid lateralization: an assessment of technique and long term results in 62 dogs with laryngeal paralysis. J. Small Anim. Pract. 30, 543-549.

Wykes, P.M. 1983. Canine laryngeal diseases part 1. Anatomy and disease syndrome. Compendium: Continnuing Education for Veterinarians. Practitioners. Vet. 5, 8-13. 